\title{
A GUERRA DO PARAGUAI EM DIFERENTES INTERPRETAÇÕES
}

\section{THE WAR OF PARAGUAY IN DIFFERENT INTERPRETA- TIONS}

Gabriel Ignácio Garcia ${ }^{1}$

Resumo: Na primeira metade do século XX as abordagens mais tradicionais acerca da Guerra do Paraguai obtiveram grande destaque e, por meio de uma análise personalista, viam o governante paraguaio Solano López como sendo responsável e causador da guerra e com certo patriotismo defendiam a ação brasileira na disputa. A partir da década de 1960, com a corrente revisionista, León Pomer (1984) e Júlio José Chiavenatto (1984) propunham a influência do imperialismo britânico como fator determinante para a deflagração de guerra e destruição do Paraguai. Mais recentemente na década de 90, uma nova linha de pesquisadores, entre eles Francisco Doratioto (2002), propunha guerra como fruto das contradições platinas e da consolidação dos Estados Nacionais na região. Posto isso, o presente artigo objetiva analisar e compreender as interpretações produzidas por essas distintas correntes historiográficas, atentando para as suas diferenças e especificidades.

Palavras-Chave: Guerra do Paraguai; Historiografia; Abordagens teóricas.

Abstract: In the first half of the twentieth century the more traditional approaches over the Paraguay War achieved highlight and, through a personalistic analysis, they put the Paraguayan ruler Solano López as being responsible and causative the war and with patriotism defended the Brazilian action the dispute. From the 60s, on the revisionist current, Júlio José Chiavenatto (1984) and Leon Pomer (1984) proposed the influence of British imperialism as factor determinant for the outbreak of war and destruction of Paraguay. More recently in the 90s, a new line

${ }^{1}$ Estudante de graduação em História da Universidade Estadual de Londrina (UEL). Orientadora: Prof. Dr. ${ }^{a}$ Edméia Ribeiro. 
of researchers, among them Francisco Doratioto (2002) suggested the war as the result of contradictions platinum and consolidation of national states in the region. Collocate thus, this article aims to analyze and understand the interpretations produced by these different historiographical currents, noting their differences and specificities.

Key words: War of Paraguay; Historiography; Approaches theory.

\section{Introdução}

Ao longo do final do século XIX e ao longo do XX foram sendo construídas diferentes interpretações acerca da Guerra do Paraguai. Militares, jornalistas, historiadores entre outros lançaram uma gama de perspectivas sobre a guerra. Há de ter em vista que tais perspectivas de análise estão situadas em contextos históricos e políticos distintos e, sendo assim, foram motivadas por interesses e/ou ideologias diferentes. Procuraremos então compreender algumas das versões elaboradas acerca da guerra principalmente no meio historiográfico, atentando para as diferenças e características próprias de cada autor e cada linha de interpretação. Atualmente são apontados três momentos distintos na produção acerca da guerra, como coloca Ana Paula Squinelo,

[...] o primeiro, que abrange os livros escritos no período que se estende da década de 1920 até a década de 1960 do século XX, oferecendo uma visão "patriótica" do conflito, como por exemplo, as obras de Fragoso e Pombo; o segundo, que compreende os estudos divulgados a partir da década de 1960, que desenvolvem a visão "imperialista" do litígio, como os de Pomer e Chiavenato; e finalmente, o terceiro, que agrupa obras editadas a partir da década de 1980, dentre as quais destacam-se os livros de Doratioto e Sales, inovadores e menos tendenciosos. (Squinelo, 2002: 21) 
Partindo dessa divisão é possível perceber como a guerra do $\mathrm{Pa}$ raguai suscitou e atualmente continua a suscitar diferentes motivações no seu estudo. A própria nomenclatura "guerra do Paraguai" é problemática. ${ }^{2}$ Enquanto a maioria dos autores a utilizam, outros preferem intitular o conflito de outras maneiras. Dentre os títulos mais comumente empregados encontra-se: "Guerra da Tríplice Aliança”, "Guerra contra o Paraguai", ou ainda, "Guerra da Tríplice Aliança contra o Paraguai"3. Alguns estudiosos utilizam mais de uma nomenclatura, como é caso de Luiz Souza Gomes (1966) que em seu texto usa tanto "Guerra das quatro nações" como "guerra do Paraguai". Entre essas várias possibilidades, optamos por fazer uso de "guerra do Paraguai" no decorrer do texto.

No presente trabalho procuraremos compreender primeiramente a corrente mais tradicional, em seguida a revisionista e posteriormente a neo-revisionista (como intitulam alguns pesquisadores). O leitor poderá notar que, para cada uma das respectivas correntes selecionamos dois autores que possuem a mesma linha de pensamento sobre a guerra.

\section{As correntes historiográficas}

Começaremos analisando a corrente mais tradicional ou "patriótica", como caracteriza Squinelo. As obras desse período tiveram forte

\footnotetext{
${ }^{2}$ Os pesquisadores da corrente historiográfica tradicional usaram amplamente o titulo "Guerra do Paraguai" o que favoreceu a sua disseminação principalmente na primeira metade do século XX.

${ }^{3}$ Nomenclaturas comumente empregadas pelos autores revisionistas e neorevisonistas.
} 
influência do positivismo e também dos relatos e escritos de militares que participaram na guerra e que foram publicados no final do XIX e início do XX - entre esses relatos cabe destacar a obra "Reminiscências da Campanha do Paraguai", do general brasileiro Dionísio Cerqueira que participou do conflito. Em tal relato, o general caracteriza Solano como sendo um ditador, e que viu na invasão do Brasil ao Uruguai um pretexto para o rompimento das relações com o Brasil e o início da guerra (Cerqueira, 1980).

A exaltação da pátria, do exército e dos grandes nomes que tiveram participação na guerra como Duque de Caxias e D. Pedro II, é um traço marcante desse momento. Vale aqui lembrar a abordagem feita sobre o tema no ensino público daquele momento, onde segundo Squinelo, "os educandos que passaram pelos bancos escolares naquela época aprenderam que a nação brasileira cumpriu "grande e significativa missão" na Guerra do Paraguai, isto é, libertou a população do "tirano" paraguaio" (Squinelo, 2011: 21). Tal visão estava mais preocupada em incutir nos alunos o sentimento de exaltação à pátria do que de fato problematizar o conflito e refletir sobre as suas consequências.

Dentre os autores que defenderam tal versão sobre a guerra, optamos por apresentar a análise feita por Luiz Souza Gomes (1966) em seu texto "Guerra das quatro nações" que representa bem as interpretações dessa corrente mais tradicional. Gomes estabelece um paralelo entre Brasil e Paraguai, colocando de um lado o Brasil como possuidor de uma nação de índole pacífica e que repelia a guerra como meio para a solução dos conflitos entre as nações e, do lado oposto o Paraguai, que 
no período posterior à sua independência passou a se constituir como um país belicoso e armado. O foco principal da interpretação personalista de Gomes é a figura de Solano López, que na visão do autor foi o grande responsável pelo conflito.

Gomes em seu texto levanta aspectos da vida de Solano, caracterizando em determinados momentos o presidente paraguaio com termos como "despótico" e "alucinado", apontando que o mesmo cresceu sob a rígida severidade de seu pai Antonio Carlos López, sem tolerância, afetividade e carinho - de modo que nem mesmo Padre Maíz e os responsáveis por sua educação teriam conseguido transformar o caráter do jovem Solano. De acordo com o autor, o pai de Solano López “já velho, via com horror agravarem-se os sentimentos agressivos do filho, e pressentiu a catástrofe que ele preparava para o país" (Gomes, 1966: 237). Além disso, Gomes descreve algumas das supostas ações que teriam sido praticadas pelo governante paraguaio, atitudes estas sempre caracterizadas por truculência e crueldade, como se observa nesse trecho abaixo:

De recuo em recuo, Lopez alcançava os confins do Paraguai, conduzindo consigo os restos lamentáveis de um exército destroçado. E na medida em que se retirava, obrigava a população civil a segui-lo: na retaguarda do exército ia a legião de velhos, mulheres e crianças maltrapilhos, descalços e quase nus, sofrendo as mais horríveis privações, pois nada se cultivava, a não ser o ódio contra o inimigo implacável que o perseguia. (Gomes, 1966: 241) 
Outro autor, cuja interpretação possui semelhanças com a de Gomes, é o historiador Rocha Pombo ${ }^{4}$, que em sua obra "Nossa Pátria" (1917) também apontava Solano, como sendo o principal responsável pela guerra. Ao descrever as atitudes do comandante paraguaio, o autor, frisa a crueldade e maldade com que o mesmo tratava seus amigos e pessoas mais próximas de seu convívio. De acordo com Pombo,

[...] é o ditador do Paraguai, Francisco Solano López, que vai renovar as pretensões de Rosas, de formar no Prata um grande império, rival do Brasil. Para isso preparava-se solícita, mas dissimuladamente; e só aguardava agora, um pretexto para entrar em cena. (Pombo, 1960)

É possível observar que em tais interpretações, os motivos da guerra são buscados nas ações de um indivíduo isolado, no caso Solano. Nelas não é buscada uma reflexão e problematização dos acontecimentos, mas observa-se mais um modelo de análise factual, oficial, que lança estereótipos tanto sobre o Paraguai quanto sobre Solano López. O interesse político em tal visão sobre a guerra é defender, justificar e exaltar a ação do Brasil na guerra - notando-se também que algumas das

\footnotetext{
${ }^{4}$ Pombo foi jornalista, professor, poeta e historiador, trabalhou na área jornalística fundando e dirigindo "O Povo" (1879). Publicou, além de livros de poesias, diversos importantes livros sobre variados assuntos. Dos livros de Rocha Pombo destacam-se: "Nossa Pátria" (1917) - com mais de 40 edições, "História da América" (1900), "História Universal" (1929), "História do Paraná" (1900), "Dicionário de sinônimos da Língua Portuguesa" (1914), "A religião do belo" (1882), "No hospício" (1905), "Visões" (1891), "Dadá" (1882) e vários outros, abrangendo os gêneros mais diversos. Além disso, foi membro da Academia Brasileira de Letras ocupando a cadeira de número 39 em 1933.
} 
informações trazidas em certas interpretações não possuem qualquer base em uma análise documental.

O que se viu a partir da década de 60 foi o surgimento de outra linha interpretativa para o conflito platino. Tal corrente foi denominada de "revisionista", pois se propunha a efetuar uma revisão sobre a guerra de modo a questionar a ideia de que Solano teria sido o único responsável pelo conflito e, neste caso, cabe entender o contexto histórico em que se dá o surgimento desta corrente historiográfica. As respectivas produções situam-se em um momento em que vários países da América Latina estavam sob o regime de ditaduras militares e, sendo assim, as publicações daquele período levantavam questionamentos sobre a atuação do exército brasileiro na guerra. Pode-se colocar também que aliado a isso houve uma espécie de inversão de papéis, visto que o Brasil deixou de ser visto como um grande "herói" para ser visto como culpado pela devastação do Paraguai e este, por sua vez, deixou de ser apontado como culpado pela guerra para assumir a posição de vítima do imperialismo inglês.

Em suas pesquisas, o historiador argentino Leon Pomer ${ }^{5}$ levanta à tese da influência do imperialismo britânico na guerra (que por sua vez é caracterizada no início da obra pelo autor como uma "guerra suja") e

\footnotetext{
${ }^{5}$ Leon Pomer ministrou vários cursos em Universidades brasileiras e argentinas e lançou obras de grande destaque voltadas a análise da guerra, sendo elas "Guerra do Paraguai: a grande tragédia rio-platense" (1981), "Guerra do Paraguai: grande negócio", do original "La Guerra del Paraguai: Gran Negócio!" (1981) e "Paraguai: nossa guerra contra esse soldado" (1984), tendo a primeira edição sido lançada em 1981 e cujos principais apontamentos veremos na continuidade do texto.
} 
indica para os fatores econômicos como sendo determinantes. A obra de Pomer é publicada em solo argentino em 1968. Sendo assim, encontrase situada em um período histórico marcadamente ditatorial, que havia se iniciado dois anos antes com o Golpe de Estado encabeçado pelo general Juan Carlos Onganía (1914-1995).

$\mathrm{O}$ autor discorre que na década de 1860 a Inglaterra se viu diante de um grande problema, ou seja, a guerra da Secessão que prejudicou o fornecimento de algodão às suas fábricas e, assim, a potência ultramarina se viu então forçada a buscar outras fontes de fornecimento de algodão e cereais. Diante de tal necessidade era preciso buscar aliados que aceitassem organizar as suas economias em função dos interesses ingleses. E algumas regiões da bacia do Rio da Prata poderiam ocupar tal posição, porém o Paraguai se punha como sério obstáculo. Na visão do autor o país guarani era visto da seguinte maneira:

Ovelha negra - Tal é o Paraguai aos olhos da burguesia inglesa e de outras burguesias europeias altamente desenvolvidas, e tal se torna, logo aos olhos de alguns cavalheiros que no Prata e no Brasil traficam e comercializam com as potências Ultramar, sem se preocuparem com outra coisa, a não ser seus interesses mesquinhos e restritos interesses de classe. (Pomer, 1984: 12)

Desta forma, o Paraguai se diferenciara dos demais países vizinhos pelo seu avançado desenvolvimento, e por (diferentemente dos demais) não possuir em sua estrutura classes que estivessem dispostas a renegar os interesses nacionais em detrimento de seus interesses de grupo. Diante de tal situação, na visão do historiador argentino, a formação 
da Tríplice aliança não se deu de maneira acidental ou circunstancial, pelo contrário, tinha um objetivo claro e específico que consistia em “[...] estruturar nessa parte do mundo, um sistema econômico-político de relações e dependências em função dos interesses das grandes potências "centrais", das quais a Grã Bretanha é inquestionavelmente a principal" (Pomer, 1984: 30).

Pomer aponta para os empréstimos contraídos no Brasil e nos demais países aliados de modo a afirmar que "a guerra foi paga, basicamente, com dinheiro fornecido pelos ingleses" (Pomer, 1984: 40). Para dimensionar os grandes valores tomados em empréstimo, o autor aponta para os dados contidos em uma carta do Ministro da Fazenda do então presidente Bartolomé Mitre, datada de 1865, onde os empréstimos de Buenos Aires, do Brasil, o empréstimo particular Baring ${ }^{6}$, o embargo de mercadorias paraguaias e finalmente os donativos para a guerra, somados, atingiam a soma de mais de dois milhões de libras. Sendo assim, a guerra do Paraguai em tal eixo explicativo, serviu para aumentar ainda mais a dependência e subordinação de Argentina e Brasil frente à potência ultramarina (Pomer, 1984: 45).

Posteriormente, no Brasil, o jornalista brasileiro Julio José Chiavenatto lançou a primeira edição do livro "Genocídio Americano: a guerra do Paraguai" (1979), que teve grande repercussão tanto no meio acadêmico como com o público em geral. Logo no prefácio de sua obra Chiavenatto critica seriamente as "barreiras" que impediam de chegar às

\footnotetext{
${ }^{6}$ Empréstimo efetuado por Norberto de La Riesta junto a Casa Baring Brothers, situada na Inglaterra.
} 
respostas sobre a guerra. A principal dessas "barreiras", segundo ele, seria "a manipulação da onda de patriotismo que os historiadores oficiais criaram descrevendo fenômenos esparsos dessa guerra, para denunciar a posição crítica como antipatriótica" (Chiavenatto, 1988: 09). Em seguida ele indica que tais historiadores não abordavam a guerra de uma maneira crítica, mas estariam fazendo "da sua alienação um exercício de cata às pulgas dos detalhes históricos" (1988: 13). Posto isso, ele deixa clara a crítica às abordagens sobre a guerra que haviam sido feitas até então, principalmente pelos historiadores tradicionais presos aos detalhes das batalhas e números do conflito.

Chiavenatto reitera que não é um historiador, mas se propõe a uma abordagem crítica sobre a guerra levando em conta o seu aspecto fundamental, ou seja, "os interesses do capital inglês" e também os aspectos políticos e militares. Ao caracterizar o Paraguai no capítulo II, o mesmo é descrito como sendo o mais progressista da América do Sul, destacando-se por, já em 1840, não possuir analfabetos e por apresentar:

[...] toda uma estrutura sócio-econômica atendendo plenamente aos interesses populares e estando livre de burocratas, cortesãos e parasitas do gênero: no Paraguai só existe trabalho produtivo. Não há dívida externa - algo absolutamente impensável dentro das normas de governo de El Supremo. O país pronto para o desenvolvimento só não é pleno pelas altas taxas de juros que Buenos Aires cobra para permitir a saída de seus produtos. (Chiavenatto, 1988: 27)

No capítulo VI intitulado "O imperialismo inglês não quer mudanças no mundo", fica clara a tese, defendida pelo autor, da influência 
inglesa na guerra, a começar pelo próprio título. Segundo Chiavenatto, no século XIX a Inglaterra dominava as relações comerciais externas, porém dois problemas se colocaram: a Guerra da Secessão (que acarretou no corte de fornecimento de algodão) e os movimentos nacionalistas nas colônias inglesas (que geraram alto custo com forças de ocupação). Esses fatores levaram à necessidade de buscar outros fornecedores de algodão e o Paraguai apontou como uma opção. Porém, o autor observa que se estabeleceu então uma contradição no sistema imperialista inglês, visto que o Paraguai já possuía um parque industrial em desenvolvimento e a Inglaterra, ao adquirir o algodão paraguaio, percebe que corria o risco de ter o Paraguai como um forte concorrente no Plata. A nação guarani, na visão do jornalista, se apresentava como um país autônomo, que não se encaixava no sistema imperialista britânico e que sendo assim poderia se constituir como uma ameaça à manutenção do status quo inglês. Como propõe Chiavenatto, o Paraguai,

[...] esse país, essa autônoma república com uma economia própria e insubmissa à exploração do imperialismo inglês, pode modificar o status quo no Plata, possibilitando muito possivelmente a atração de outros interesses de outras potências. A grande máquina do capitalismo internacional não pode ter uma pequena peça destoando da engrenagem. É fácil perceber que o Paraguai será vitima desse sistema internacional - os ingleses, do seu ponto de vista imperialista, dominador, violento e desprovido de qualquer ética, guiados apenas pelo cálculo econômico, estão certos: é preciso destruir e substituir a pequena engrenagem que não se ajusta à máquina. (Chiavenatto, 1988: 79-80)

O Paraguai, nas linhas deste autor, assume então uma posição de vítima frente à dominação do imperialismo britânico e este, por sua vez, 
se aloca como um processo pré-determinado, dotado de uma dinâmica avassalante. Para atestar a influência e o interesse da Inglaterra na guerra, aponta para os volumosos empréstimos que teriam sido feitos tanto pelo Brasil quanto por Argentina e Uruguai, totalizando mais de sessenta e um milhões de libras esterlinas. Desse total, Brasil e Argentina teriam recebido as maiores somas, sendo que o primeiro teria recebido trinta e um milhões e o segundo vinte e sete milhões de libras. Para Chiavenatto, o que se constitui na guerra do Paraguai "é um processo determinado, escapa ao controle de governos e homens", cuja mecânica é avassaladora e sua marcha é irreversível (Chiavenatto, 1988: 83). Posto isso, complementa, a diplomacia que se estabeleceu e os conflitos entre os países sul-americanos foram apenas "caudatários das necessidades econômicas" do capital inglês.

Como foi possível de ser observado, os apontamentos de Pomer e Chiavenatto possuem diversas aproximações - ambos defendem a ação do imperialismo inglês como fator determinante para o desencadeamento da guerra. Percebe-se, como argumenta Squinelo, nas leituras dos autores denominados revisionistas

[...] uma dose de emoção e envolvimento na escrita da história, ao mesmo tempo em que nos destituía de nosso papel de sujeitos históricos, ao desconsiderar todos os problemas que envolviam o Prata, e buscar a resposta para essas questões, em um elemento externo. (Squinelo, 2002: 22-23)

Nas décadas de 1980 e 90 o que se viu foi o aparecimento de novas abordagens sobre a guerra questionando algumas das ideias defen- 
didas até então pelos autores ditos revisionistas. Ricardo Salles (1990), Wilma Peres Costa (1996), Maria Eduarda Magalhães Marques (1995), André Toral (2001), Vitor Izecksohn (2001, 2004) e Francisco Doratioto (1991, 1996, 2002) são alguns dos pesquisadores que procuraram por meio de uma metodologia de pesquisa, pautada em um rico acervo documental, compreender a guerra do Paraguai tendo em vista a dinâmica política e social específica de cada um dos países envolvidos e as relações de interesse entre esses países na região da Prata em um momento de constituição das identidades nacionais. Alguns destes historiadores lançaram novas abordagens acerca da guerra, como é caso de Ricardo Salles e André Toral que, em suas obras, discorrem e problematizam as imagens produzidas ao longo do conflito. Embora todos os autores acima citados ofereçam importantes perspectivas de análise, optamos por escolher dois autores cujas considerações configuram-se como expoentes nessa recente linha de interpretação da guerra, no caso da historiografia brasileira ${ }^{7}$. São eles: Francisco Fernando Monteoliva Doratioto e Ricardo Henrique Salles. ${ }^{8}$

\footnotetext{
${ }^{7}$ Analisar mais detalhadamente as pesquisas de cada um dos autores que integram tal corrente historiográfica tornaria o texto por demais extenso, em virtude disso, optamos por fazer tal escolha.

${ }^{8}$ Ricardo Salles constitui-se em um dos pesquisadores que trouxe notáveis contribuições nessa nova corrente de estudos sobre a guerra. Historiador, formado pela Pontifícia Universidade Católica do Rio de Janeiro (1996), tendo mestrado (1999) e doutorado (2001) em História pela Universidade Federal Fluminense, Salles lançou em 1990 o seu livro "Guerra do Paraguai: escravidão e cidadania na formação do exército", trazendo importantes considerações sobre o tema e valendo-se de uma vultosa documentação.
} 
Salles levanta algumas críticas às versões revisionista e tradicional da guerra, apontando que se por um lado os historiadores tradicionais erraram por um excesso de factualismo e oficialismo, por outro, os revisionistas também pecaram por, em muitos momentos, pautarem-se em simplificações. Como assinala o autor, a corrente revisionista

[...] tem o seu ponto fraco talvez exatamente naquilo que caracterizou a sua novidade: a inserção do conflito no contexto mais geral de expansão do capitalismo. A supervalorização da ação direta da Inglaterra e a subestimação das motivações particulares das nações envolvidas (à exceção do Paraguai) acabaram por obscurecer a originalidade da abordagem. (Salles, 1990: 37)

Destacada a crítica, o autor parte para o objeto central de seu estudo onde procura compreender a forma como se deu a constituição de um exército profissional durante a guerra e a maneira como este se relacionou com a sociedade daquele contexto histórico, principalmente tendo em vista tais relações com as camadas mais populares da sociedade e os escravos. Para tanto, o historiador procura traçar um quadro geral da sociedade brasileira e da sua política externa antes do conflito. No quadro político, nas relações entre o Brasil e as potências estrangeiras, o mesmo procurava acentuar as suas diferenças com relação aos países vizinhos latino-americanos, apresentando-se como sendo mais forte politicamente. Nesse quadro o Império brasileiro mantinha o firme propósito de afirmar e legitimar os seus interesses mantendo o controle da nação de maneira centralizada. Entre tais interesses destaca-se a garantia da livre navegação na Bacia do Prata e as reinvindicações territoriais nas 
áreas fronteiriças. Diante disso, a guerra do Paraguai foi ao mesmo tempo parte e fruto de um processo de transformações na sociedade brasileira em um período de transição do escravismo para o capitalismo - juntando-se a isso a fundação do partido republicano e o desenvolvimento do movimento abolicionista.

Como argumenta Salles, antes da guerra o contingente do exército sempre fora muito pequeno. Sua estruturação se dava a partir da Guarda Nacional que era empregada em determinados momentos na resolução de conflitos regionais e nas pendências com os países vizinhos, sendo que em muitos casos também acabava servindo aos interesses de autoridades locais. Diante da guerra que se apresentava, o Brasil se viu forçado a estruturar e organizar um exército profissional. Para tanto,

[...] o governo imperial desenvolveu um recrutamento de dimensões nacionais. Além do aspecto geográfico - sua escala nacional - cabe ressaltar sua dimensão social. Recrutar, vestir, armar, treinar, organizar, transportar, prover as necessidades mínimas e motivar 100.000 homens foi algo que atingiu o conjunto da sociedade. (Salles, 1990: 59)

Diante desse esforço de recrutamento é significativo o número de escravos que combateram do lado brasileiro, estimado pelo pesquisador em $10 \%$ do conjunto das tropas. A participação de parte dessa parcela da população que vivia à margem da sociedade evidenciou uma "contradição entre a estrutura político-jurídica liberal do Império e sua base escravocrata" (Salles, 1990: 74). Nos anos pós-guerra, o que se viu foi 
um aumento do número de fugas e rebeliões, além da busca por direitos por parte de uma parcela dos escravos.

Salles também assinala a importante participação na guerra de indivíduos oriundos de camadas populares livres da sociedade que ingressaram no exército por meio do Corpo de Voluntários da Pátria - principalmente no começo da guerra, motivados pelo sentimento de patriotismo que aflorou no seio da sociedade. Porém, com o desenrolar do conflito e o enfraquecimento de tal sentimento, o grosso do exército brasileiro foi organizado de maneira coercitiva pelas autoridades locais e regionais no interior do Império. $\mathrm{O}$ autor frisa que tal mobilização não trouxe plenos direitos de cidadania para essas pessoas, mas contribuiu significativamente para a "desmoralização do Império" (Salles, 1990: 81).

O exército, ao ser composto, durante a guerra, por sujeitos provenientes das camadas sociais mais baixas e marginalizadas, de certa forma foi afetado e passou a ter vínculos com outras camadas populares e médias da sociedade, como indica o autor:

O exército, depois da guerra do Paraguai, não deixou de ser o braço armado do regime imperial. [...] O que de fato ocorreu é que o aparato repressivo passou de uma estrutura, em grande parte, diretamente ligada ao poder local e regional da classe dominante para uma corporação que entretinha vínculos necessários com outros grupos sociais. Uma corporação mais permeada pelas contradições do todo social que se complexificava. (Salles, 1990: 111) 
Como argumenta na conclusão de seu trabalho, o exército no pósguerra passou a ter um peso muito maior na vida política do país de forma que a Proclamação da República em 1889 teve os militares com uma posição de destaque no decorrer dos acontecimentos. Para este estudioso, outros momentos históricos ao longo do século $\mathrm{XX}$, como a Revolta tenentista de 20 e o Golpe militar de 1964, também evidenciam isso. Em contextos históricos distintos,

com conteúdo político mais à direita [...] ou à esquerda, a ação politica dos militares sempre guardou dois componentes importantes: algum tipo de vinculação com os setores médios e um discurso em nome dos interesses nacionais e do povo. (Salles, 1990: 152)

Outro dos expoentes dessa nova corrente historiográfica é o historiador brasileiro Francisco Doratioto. ${ }^{9}$ Ao comentar sobre as interpretações feitas até então pela historiografia conservadora e pelo revisionismo histórico, Doratioto, logo na introdução de "Maldita guerra", teceu uma séria crítica a ambas as abordagens, pois segundo ele,

\footnotetext{
${ }^{9}$ Francisco Doratioto possui mestrado (1988) e doutorado (1997) em História pela Universidade de Brasília. Atuando atualmente como professor adjunto II, de História da América, no Departamento de História da Universidade de Brasília, é autor da obra "Maldita guerra: nova história da guerra do Paraguai" (2002), que se constituiu como o fruto de aproximadamente quinze anos de pesquisa em bibliotecas e acervos históricos no Brasil, no Paraguai, Uruguai, Argentina e Europa. Em sua tese observa-se a utilização de uma farta documentação, sendo que algumas delas eram inéditas até então e, aliado a isso, destaca a metodologia de análise de fontes empregada em seu trabalho.
} 
Na verdade, tanto a historiografia conservadora como o revisionismo simplificaram as causas e o desenrolar da Guerra do Paraguai, ao ignorar o documento e anestesiar o senso crítico. Ambos substituíram a metodologia do trabalho histórico pelo emocionalismo fácil e pela denúncia indignada [...] Dessas atenuantes, porém, não se beneficia o revisionismo, em sua vertente antiimperialista [...] Contudo, continuar a defender, hoje, essa interpretação somente pode ser resultado da ignorância histórica ou, então, da natural dificuldade de se reconhecer errado. (Doratioto, 2002: 20)

Doratioto rejeita a hipótese da influência do imperialismo britânico defendida pelos revisionistas e coloca que tal visão serviu à defesa de interesses políticos entre as décadas de 1960 a 1980. Parte da historiografia, ao defender a possibilidade de construção na América Latina de modelos de desenvolvimento autônomo, colocou o Paraguai de Solano López como um modelo que poderia ter seguido por sua não dependência em relação às potências centrais, e por seu grande desenvolvimento. Porém, como destaca Doratioto, tais autores acabaram por negar tal possibilidade a partir do momento em que colocaram a Grã-Bretanha como "onipotente" e sendo capaz de impedir o desenvolvimento de países não dependentes. Da mesma forma, o oficialismo paraguaio fez uso da imagem de Solano como vítima para defender os seus interesses ao longo da ditadura de Stroessner.

Ao refutar a influência da Inglaterra na guerra, Doratioto argumenta que os diplomatas ingleses que negociavam com o governo de Solano seguiram as instruções do governo britânico, no sentido de impedir que o Paraguai envolvesse a Inglaterra em suas disputas com países vizinhos e garantir assim a livre navegação de embarcações inglesas 
nos rios Paraguai e Paraná. Junta-se a isso, o rompimento das relações diplomáticas entre Brasil e Inglaterra em 1863 devido ao bloqueio naval britânico na costa do Rio de Janeiro, encarado como uma humilhação pela opinião pública brasileira - e o fato que durante o conflito o representante inglês em Buenos Aires propiciava, por meio da mala diplomática britânica, comunicações frequentes de Solano com o exterior. O historiador também apresenta e analisa uma carta datada de 07 de dezembro de 1864, escrita pelo representante britânico Edward Thornton e endereçada ao chanceler paraguaio José Berges, em um momento em que as relações entre Paraguai e Império estavam cortadas. No conteúdo de tal carta, Edward Thornton deplora o rompimento das relações diplomáticas do Paraguai para com o Brasil e manifesta o desejo de que houvesse uma reconciliação entre os dois países, colocando-se à disposição para auxiliar na resolução do impasse. (Doratioto, 2002: 90)

Tanto Chiavenatto como Pomer, como vimos anteriormente, usaram as altas somas dos empréstimos feitos pelos países aliados junto a banqueiros ingleses para fundamentar o interesse que a Inglaterra tinha na guerra. Segundo Doratioto, o fato de os países aliados terem recebido mais empréstimos do que o Paraguai se justifica pelo fato de que a partir de 1865 o mesmo passou a estar em desvantagem econômica, financeira e populacional em relação aos membros da tríplice aliança. Como bem lembra o autor, "o capital não tem ideologia e busca a melhor remuneração ao menor risco" (Doratioto, 2002: 91). Sendo assim, naquele momento, ceder empréstimos ao governo paraguaio seria uma decisão de grande risco diante da impossibilidade do país guarani ganhar a guerra. 
Para Doratioto, ao se pensar a guerra do Paraguai não se deve procurar "mocinhos" ou "bandidos" como teria feito o revisionismo, mas faz-se necessário ter em vista que a mesma ocorreu em um momento de constituição dos Estados Nacionais, onde cada um dos países envolvidos no conflito possuía e defendia seus próprios interesses, como ressalta o autor:

A guerra do Paraguai foi fruto das contradições platinas, tendo como razão última a consolidação dos Estados nacionais na região. [...]. A guerra era uma das opções possíveis, que acabou por se concretizar, uma vez que interessava a todos os Estados envolvidos. [...]. A guerra era vista por diferentes ópticas: para Solano López era a oportunidade de colocar o seu país como potência regional e ter acesso ao mar pelo porto de Montevidéu, graças a uma aliança com os blancos uruguaios e os federalistas argentinos representados por Urquiza; para Bartolomé Mitre era a forma de consolidar o Estado centralizado argentino, eliminando os apoios externos aos federalistas, proporcionados pelos blancos e por Solano López [...]; para o Império, a guerra contra o Paraguai não era esperada, nem desejada, mas, iniciada, pensou-se que a vitória brasileira seria rápida e poria fim ao litígio fronteiriço entre os dois países e às ameaças à livre navegação, e permitiria depor Solano López. (Doratioto, 2002: 96)

Doratioto conclui sua pesquisa apontando para os efeitos da guerra, de forma que esta proporcionou uma alteração no plano regional das relações entre os países envolvidos. Sobre o Paraguai, o pesquisador coloca que o conflito significou a perda das disputas territoriais com seus países vizinhos, a destruição do Estado existente e de sua economia de tal maneira que. Aliado a isso, destacam-se as perdas de vidas paraguaias girando em torno de $8,7 \%$ a $69 \%$ de uma população estimada 
entre 285.715 a 450.000 habitantes. Esses números apresentados pelo autor se pautam em estudos mais recentes e destoam dos números apresentados pelos revisionistas anteriormente. ${ }^{10}$

No Império, a guerra inesperada mostrou o despreparo militar brasileiro para tal empreitada. Porém, com a vitória, o exército saiu fortalecido do campo de batalha passando a adquirir uma nova identidade e a dissociar-se da monarquia de tal modo que, mais tarde, desempenhou um papel de grande importância na Proclamação da República em 1889. No que tange à relação entre Brasil e Argentina, o historiador destaca que durante 1862 e 1868 houve uma política de colaboração entre as duas partes, o que se deve em grande parte ao fato de que em ambos os países os partidos liberais estavam no poder. Porém, em 1868, nestes dois países os partidos conservadores (críticos de tal aliança) substituíram seus rivais no poder, tendo como consequência no pós-guerra uma política externa em que Brasil e Argentina "rivalizaram-se para impor a sua influência na reconstrução institucional e na definição territorial do Paraguai [...]" (Doratioto, 2002: 485).

\section{Considerações finais}

No desenrolar do texto foi possível perceber como a guerra do $\mathrm{Pa}$ raguai foi interpretada por pesquisadores de diferentes correntes historiográficas, desde o fim do século XIX e no decorrer do XX. Estudiosos,

\footnotetext{
${ }^{10}$ A título de comparação, Chiavenatto, em "Genocídio Americano", estima o número de habitantes paraguaios em 800.000 no período anterior ao conflito e indica que $75 \%$ da população teriam morrido ao término da guerra.
} 
inseridos em contextos históricos e sociais distintos, analisaram o conflito de diferentes ângulos. Os tradicionais que por meio de uma análise personalista viam o governante paraguaio Solano López como sendo responsável e causador da guerra e com certo patriotismo defendiam a ação brasileira na disputa. A partir da década de 1960, a corrente revisionista, propôs a influência do imperialismo britânico como fator determinante para a deflagração de guerra e destruição do Paraguai. Mais recentemente na década de 1990, os pesquisadores neo-revisionistas indicaram que a guerra teria se constituído como fruto das contradições platinas e da consolidação dos Estados Nacionais na região.

Ressalta-se a importância da guerra do Paraguai nos estudos históricos. Tendo em vista que o mesmo, "foi o conflito externo de maior repercussão para os países envolvidos, quer quanto à mobilização e perda de homens, quer quanto aos aspectos políticos e financeiros" (Doratioto, 2002: 17). Por fim, é importante apontar que na historiografia brasileira, atualmente, as teses apresentadas por Salles e Doratioto, entre outros pesquisadores, apresentam-se como sendo as mais aceitas, tendo em vista a base documental em que tais autores pautam as análises e as metodologias que empregaram nas interpretações sobre o conflito.

\section{Referências bibliográficas}

CERQUEIRA, Dionísio. Reminiscências da Campanha do Paraguai. Rio de Janeiro: Biblioteca do Exército, 1980.

CHIAVEnATTO, Julio José. Genocídio Americano: a guerra do Paraguai. São Paulo: Brasilense, 1984. 
DORATIOTO, Francisco. Maldita guerra: nova história da Guerra do Paraguai. São Paulo: Companhia das Letras, 2002.

GOMES, Luiz Souza. América Latina: seus aspectos, sua história, seus problemas. $2^{\mathrm{a}}$ ed. Rio de Janeiro: Fundação Getúlio Vargas, 1966. (1 ${ }^{\mathrm{a}}$ ed. 1961).

POMER, Léon. Paraguai: nossa guerra contra esse soldado. São Paulo: Global, 1984.

POMBO, Rocha. História do Brasil. Revista e atualizada por Hélio Vianna. 9. ed. São Paulo: Melhoramentos, 1960.

SALLES, Ricardo. Guerra do Paraguai: escravidão e cidadania na formação do exército. Rio de Janeiro: Paz e Terra, 1990.

SQUINELO, Ana Paula. Revisões historiográficas: a guerra do Paraguai nos livros didáticos brasileiros - PNLD 2011. Diálogos, Campo Grande, n. 1, p. 19-39, 2011. 